\title{
What is known about melatonin, chemotherapy and altered gene expression in breast cancer (Review)
}

\author{
CARLOS MARTÍNEZ-CAMPA ${ }^{1}$, JAVIER MENÉNDEZ-MENÉNDEZ ${ }^{1}$, \\ CAROLINA ALONSO-GONZÁLEZ ${ }^{1}$, ALICIA GONZÁLEZ ${ }^{1}$, \\ VIRGINIA ÁLVAREZ-GARCÍA ${ }^{2}$ and SAMUEL COS $^{1}$ \\ ${ }^{1}$ Department of Physiology and Pharmacology, School of Medicine, University of Cantabria and Research \\ Institute Valdecilla, 39011 Santander, Spain; ${ }^{2}$ Institute of Biological Chemistry, Biophysics and Bioengineering, \\ School of Engineering and Physical Sciences, Heriot Watt University, EH14 4AS Edinburgh, UK
}

Received May 4, 2016; Accepted November 17, 2016

DOI: 10.3892/ol.2017.5712

\begin{abstract}
Melatonin, synthesized in and released from the pineal gland, has been demonstrated by multiple in vivo and in vitro studies to have an oncostatic role in hormone-dependent tumors. Furthermore, several clinical trials point to melatonin as a promising adjuvant molecule to be considered for cancer treatment. In the past few years, evidence of a broader spectrum of action of melatonin as an antitumor agent has arisen; thus, melatonin appears to also have therapeutic effects in several types of hormone-independent cancer, including ovarian, leukemic, pancreatic, gastric and non-small cell lung carcinoma. In the present study, the latest findings regarding melatonin molecular actions when concomitantly administered with either radiotherapy or chemotherapy in cancer were reviewed, with a particular focus on hormone-dependent breast cancer. Finally, the present study discusses which direction should be followed in the next years to definitely clarify whether or not melatonin administration could protect against non-desirable effects (such as altered gene expression and post-translational protein modifications) caused by chemotherapy or radiotherapy treatments. As treatments move towards personalized medicine, comparative gene expression profiling with and without melatonin may be a powerful tool to better understand the antitumor effects of melatonin, the pineal gland hormone.
\end{abstract}

\section{Contents}

1. Introduction: Chemotherapy for breast cancer

2. Melatonin and mammary cancer: In vitro and animal studies

Correspondence to: Dr Carlos Martínez-Campa, Department of Physiology and Pharmacology, School of Medicine, University of Cantabria and Research Institute Valdecilla, Av. Cardenal Herrera Oria s/n, 39011 Santander, Spain

E-mail:martinezcm@unican.es

Key words: cancer, breast cancer, chemotherapy, gene expression, melatonin
3. Melatonin and cancer: Clinical trials

4. Can melatonin enhance the beneficial and protect against the deleterious effects of chemotherapy?

5. Conclusions

6. Melatonin and cancer: What next?

\section{Introduction: Chemotherapy for breast cancer}

According to the World Cancer Research Fund International, breast cancer is the most frequent type of tumor suffered by women in the world, with $\sim 1.7$ million newly diagnosed cases in 2012 (1). Approximately 1 in 8 women will develop a mammary tumor during her lifetime. The American Cancer Society's report for the USA in 2015 informs of 231,840 new cases of invasive breast cancer, 60,290 women with carcinoma in situ and 40,290 mortalities (2). In addition, breast cancer is the second cause of mortality by cancer in women, only exceeded by lung tumors (3). The mortality rates for breast cancer have been declining since 1989, particularly in premenopausal women, probably as a result of earlier detection as well as improved treatments (4). One fact that may also explain this decrease is the less frequent administration of hormone replacement therapy (HRT) following the publication of a report (the Women's Health Initiative) published in 2002, which suggests that HRT may be a risk factor that could explain the increase in the incidence of breast cancer (5).

Chemotherapy consists of treatment with cancer-killing drugs administered either intravenously or orally. Chemotherapy compounds are usually applied by intravenous infusion and, through the bloodstream, they reach growing cancer cells in almost all body tissues. Chemotherapy compounds work by targeting cells with a high rate of self-renewal, which is a hallmark of cancer cells (6). Chemotherapy is recommended following surgery (adjuvant chemotherapy): Surgery is performed to dissect the tumor, and adjuvant therapy is administered to try to eliminate any cancer cells that had not been removed by the surgery and may spread out later (7). The most frequently used adjuvant treatments to be administered subsequent to surgery are radiation, chemotherapy, targeted therapy and hormone therapy (8). 
Neoadjuvant therapy refers to treatments that are administered prior to surgery instead of subsequent to surgery. The benefits of neoadjuvant chemotherapy are that drugs may cause a decrease in the size of the tumor, thus facilitating tumor removal with a less extensive surgery (9). In addition, administering chemotherapy prior to the tumor being removed may aid the subsequent monitoring of the disease, since in case the first cocktail of drugs does not diminish the tumor size, other compounds may be considered (10). Finally, chemotherapy is also employed as a treatment strategy for patients whose tumor has spread outside the mammary gland and underarm area. Combinations of drugs are commonly used to treat mammary tumors detected in the early stages of carcinogenesis, while advanced cancer is more commonly treated with a unique chemotherapeutic molecule (11). Chemotherapy is usually administered in cycles, with periods of administration followed by resting periods to allow patient recovery and to minimize the side effects of treatment (12).

Since microtubules participate in the migration of chromosomes to opposite ends of mitotic cells during the anaphase, microtubule inhibitors (MIs), also known as microtubule-stabilizing agents, are molecules suitable to use in the treatment of mammary tumors. MI agents include microtubule depolymerizing compounds (Vinca alkaloids) and polymerizing agents (taxanes) (13). Vinca alkaloids derive from the periwinkle plant Catharanthus roseus (14). The first clinical trial demonstrating their efficacy in cancer was reported in 1963 (15). Nowadays, these compounds are produced synthetically and include vinblastine, vincristine, vindesine and vinorelbine (14). The main mechanism that explains their cytotoxicity is their capability to interfere with tubulin, with subsequent microtubule function disruption (particularly concerning microtubules implicated in the formation of the mitotic spindle apparatus), leading to mitosis disruption and finally resulting in metaphase arrest (16). These agents interfere with the assembly of tubulin by introducing a wedge between the contact surfaces of two tubulin molecules (17).

Taxanes are diterpenes obtained from Taxus brevifolia (18). The first reported taxane, named taxol, was initially isolated in 1971 (19). Taxanes present difficulties in formulation because they are poorly soluble in water, and for this reason, the first clinical trial including taxanes was not reported until 1987 (20). The other taxane currently in use is docetaxel, which is obtained from Taxus baccata (21). Both paclitaxel and docetaxel act as spindle poisons, stabilising the tubulin polymers against depolymerisation. In addition, they also promote microtubulin assembly. These two actions together block microtubule dynamics and consequently lead to cell cycle arrest (22). Taxanes induce changes in tubulin spatial conformation, which interferes with the depolymerisation of microtubules in a precise directional way, by binding a specific domain of tubulin located in the internal surface of the microtubule $(23,24)$.

Anthracyclines such as epirubicin and doxorubicin are also commonly used in chemotherapy combined with other chemotherapeutic drugs to treat breast cancer in patients who have had surgery to remove the tumor (25). Their mechanism of action is based on their ability of insertion between two DNA strands, resulting in a DNA-anthracycline complex that inhibits both DNA and RNA synthesis (26). This mechanism also targets DNA for cleavage by topoisomerase II, which leads to a cellular cascade that eventually results in cell death (27). Epirubicin is frequently selected over doxorubicin in numerous chemotherapy protocols, since it appears to have fewer side effects (28). Eribulin is a new anthracycline approved by the Food and Drug Administration of USA in 2010 to treat women with metastatic tumors who had been previously treated with at least two chemotherapeutic compounds indicated for the treatment of metastatic breast cancer (29). This drug exerts its anticancer effects by triggering a mitotic blockade, leading cancer cells to enter apoptosis (30).

Other current approaches in the treatment of breast cancer include compounds developed against specific identified targets (molecular-targeted therapies) that contribute to tumor growth (31). As an example, trastuzumab is a monoclonal antibody used to treat patients with metastatic breast cancer. Trastuzumab is indicated against tumors overexpressing the oncogene human epidermal growth factor receptor 2 (HER2)/neu, since it targets the membrane HER2/neu receptor, which normally promotes normal cell growth and is also overexpressed in certain cancerous breast tissues (32). Despite several randomized clinical trials with promising results (33), other reports indicated that both de novo and acquired resistance to trastuzumab could be developed (34). Therefore, other recently described agents have been included in the list of chemicals available to treat HER2-overexpressing mammary tumors. One of them is lapatinib, a reversible inhibitor of both epidermal growth factor receptor (EGFR) and HER2/neu tyrosine protein-kinases (35), which was approved in 2007 for women undergoing metastatic breast cancer with acquired resistance to trastuzumab (36). Lapatinib was well tolerated and displayed encouraging clinical results when used as a first-line therapy agent in ErbB2-amplified tumors, either advanced local tumors or metastatic breast cancer (37). Another molecule to be considered is HKI-272, a (Her2)/neu receptor tyrosine kinase inhibitor with an irreversible mechanism of inactivation and a demonstrated clinical activity, which is well tolerated among both high-dose trastuzumab pre-treated and non pre-treated patients with advanced ErbB2-positive mammary tumors (38). HKI-272 targets a cysteine residue located in the adenosine triphosphate-binding pocket of the ERbB2 receptor, resulting in the inhibition of the downstream signal transduction cascade triggered, and consequently altering the cell cycle regulation (39).

Among the battery of promising new chemicals, drugs that target heat shock protein (Hsp) 90 must be mentioned. Hsp90 belongs to the family of chaperones and establishes associations with a set of different proteins that are known as 'Hsp90 client proteins' (40). Multiple Hsp90 client proteins are implicated in breast tumor progression and resistance to chemotherapy treatments, including the receptor protein-tyrosine kinases of the ErbB2 family, estrogen receptor (ER), Akt and mutated versions of p53 (41). The efficacy of Hsp90 inhibitors has been well documented in several preclinical cancer models. One of these inhibitors is $17-\mathrm{AAG}$, which has completed phase I testing $(42,43)$.

Angiogenesis is a physiological process that consists in new vessel formation. When a tumorous mass of cells is growing, angiogenesis is crucial to maintain both tumor growth and progression (44). Therefore, numerous drugs have been tested during the past decades in the hope of identifying specific inhibitors of the different pathways necessary for angiogenesis (45). One of the key molecules in the formation 
of new vessels is vascular endothelial growth factor (VEGF), probably the most studied angiogenic factor (46). VEGF is implicated in the progression of breast cancer and is also a potential prognosis biomarker (47). Bevacizumab (Avastin ${ }^{\circledR}$ ) is a recombinant humanized monoclonal antibody that recognises all the known variants of VEGF-A (48). To date, bevacizumab is the unique anti-angiogenic chemical with clearly demonstrated benefits in metastatic breast cancer treatment clinical trials $(49,50)$. Pazopanib is another inhibitor of VEGF receptor (VEGR) (51). Pazopanib also inhibits the signaling pathways downstream of the platelet-derived growth factor receptor and the mast/stem cell growth factor receptor c-KIT (52). Pazopanib treatment provides disease stability in patients with advanced breast cancer (53).

Estrogens are implicated in the development of the mammary gland, and are also known to be key stimulators of both the genesis and growth of mammary tumors (54). Therefore, one of the main strategies to fight breast cancer is neutralizing the stimulating actions of estrogens on the mammary gland (55). Several chemicals have been tested and commercialized, since they are selective inhibitors of the effects of estradiol on the breast. These include selective estrogen receptor modulators (SERMs), which are chemicals that directly bind to ER, thus inhibiting its actions by interfering with the binding of endogenous estrogens (56). Of these, tamoxifen $(57,58)$ and a number of its derivatives $(56)$ are the best known examples. Fulvestrant is an ER antagonist that has no agonist effect described and downregulates the protein levels of ER $\alpha$ (59). Fulvestrant is being currently administered to postmenopausal women with advanced breast cancer whose tumors are ER positive and have progressed upon receiving first-line endocrine therapy (60). Other compounds developed against estrogens are chemicals that prevent the production of steroids by downregulating the enzymes necessary for the conversion into estradiol from androgenic precursors. These drugs belong to the class known as selective estrogen enzyme modulators (SEEMs), which include both steroidal (such as formestane or exemestane) and non-steroidal (such as anastrozole and letrozole) compounds (61).

\section{Melatonin and mammary cancer: In vitro and animal studies}

Melatonin is an indolic hormone produced principally by the pineal gland. Melatonin is a ubiquitously distributed molecule with a variety of diverse functions (62). Melatonin employs a diverse set of mechanisms to regulate the physiology and molecular biology of cells (63). The majority of actions of melatonin are based on its ability to bind to melatonin membrane receptors, which are G-protein coupled receptors that trigger cellular signaling pathways (64). The pineal hormone also acts through orphan receptors or molecules such as calmodulin (65). Additionally, melatonin can detoxify free radicals and related oxygen derivatives via receptor-independent pathways (66).

Concerning tumorigenesis, numerous studies have been performed in animal models. Experimental approaches include increasing the activity of pinealocytes and administering exogenous melatonin, which cause a decrease in the number, incidence and development of chemically-induced mammary tumors (67). However, reduced levels of melatonin (for example, by removing the pineal gland) appear to stimulate breast cancer progression (68). Several reports established a lower cancer risk among totally blind women (69-71). By contrary, a moderate but significant increase in the risk of developing breast cancer among women who have been working for long periods in rotating night shifts (which implicates that they were exposed to light during the night, and consequently, the nocturnal melatonin production was inhibited) has also been documented (72).

The antiproliferative effects of melatonin on the breast cancer cell line MCF-7 have been studied for more than two decades (73). The data available suggest that the inhibitory action of melatonin on mammary cancer estrogen-positive cell lines is based on its ability to regulate either the synthesis of estrogens or estrogen signaling pathways (74). Thus, the pineal hormone is capable of downregulating both the expression and activity of the enzymes necessary for the synthesis of estrogens from androgenic precursors, therefore acting as a SEEM. In the MCF-7 cell line, melatonin at physiological concentrations exhibits anti-aromatase properties (75). The pineal hormone is able to reduce the activity of aromatase, the principal enzyme in estrogen biosynthesis. Melatonin inhibits aromatase under basal conditions or when the enzyme activity is stimulated by cyclic adenosine monophosphate (cAMP) or cortisol (76). When gene expression was evaluated and the CYP19 gene (coding for aromatase) was examined, it was observed that melatonin downregulated its expression at the transcriptional level (76). The major bloodstream circulating form of physiologically inactive estrogen is estrone sulfate, which acts as an estrogen reserve (77). The enzyme steroid sulfatase (STS) converts inactive estrogen sulfates into estrone and estradiol. Estrone can be further transformed into physiologically active estrogen by the action of $17 \beta$-hydroxysteroid dehydrogenase type 1 (17 $\beta$-HSD1). Finally, the enzyme estrogen sulfotransferase (EST) sulfonates estrogens to form biologically inactive estrogen sulfates. Both enzymes, STS and EST, serve a role in the modulation of the in situ levels of estradiol in hormone-dependent tumors (78). Melatonin modulates the expression and activity of aromatase, STS, 17 $\beta$-HSD1 and EST not only in tumor cells, but also in surrounding cells such as fibroblasts and endothelial cells (74,79-82).

Melatonin can also counteract the different actions of estrogens, thus functioning as a naturally occurring SERM (83). The mechanisms implicated in the antiestrogenic effects of melatonin are yet being elucidated. Unlike other antiestrogenic molecules such as tamoxifen, melatonin does not directly bind to ER (84). In estrogen-positive breast cancer cells, melatonin decrease the expression of ER $\alpha$ (85) and impairs the estrogen-mediated transcriptional activation of genes through destabilization of the estradiol-ER complex, preventing its binding to DNA in both estrogen response element (ERE)- and activator protein 1-containing promoters (86). This effect appears to be mediated by calmodulin, since melatonin behaves as a calmodulin antagonist. The pineal hormone promotes structural changes in the calmodulin-ER $\alpha$ protein complex, thus facilitating its binding to an ERE $(87,88)$. Remarkably, melatonin does not alter the recruitment of co-activators triggered by ER $\alpha$, suggesting that melatonin mechanisms of action diverge from those of other anti-estrogen chemicals used in breast cancer treatment (88). It is important to mention that only $\mathrm{ER} \alpha$, but not $\mathrm{ER} \beta$, binds to calmodulin (84). The substitution for glycine of two lysine 
residues located at positions 302 and 303 of the hinge domain of ER $\alpha$ generated a mutant version of $\mathrm{ER} \alpha$ that was incapable of binding to calmodulin, and that therefore turned into a melatonin non-regulated receptor (88). The effects of melatonin may also be explained in terms of binding to its specific membrane receptors, such as melatonin receptor type 1 (MT1), resulting in an interplay with the ER signaling pathway (89). MT1 receptors are present in normal human breast tissues and in tumor tissues (90). Melatonin and estradiol signaling pathways converge and they have opposite effects over cAMP intracellular concentrations. In breast cancer cells, estrogens trigger adenylate cyclase activation, which results in increased cAMP cytoplasmic levels in a classical short-time second-messenger mechanism that is independent of transcription (91). The increase in cAMP levels cooperates with long-time genomic effects of estradiol, thus enhancing ER-mediated transcriptional activation (91). By contrary, melatonin, through its specific binding to its membrane receptor MT1, inactivates adenylate cyclase, resulting in decreased cAMP levels (92).

The fact that only those human mammary cancer cell lines that are $\mathrm{ER}^{+}$are sensitive to the antimitotic actions of melatonin supports the theory that the antitumor effects of this indolamine occur through its actions on breast cancer cells' estrogen-responsive pathways (93). Melatonin is able to block, under different culture conditions, the mitogenic effects of estradiol (94). The antiproliferative effect of this indolamine could be explained through the modification of the levels of estrogen-modulated proteins, several growth factors and proto-oncogenes such as cMYC, transforming growth factor (TGF) $\alpha$, Trefoil factor 1, also known as pS2, progesterone receptor (PGR), AP1 transcription factor subunit c-fos and TGF $\beta$ in human estrogen-positive breast cancer cell lines $(94,95)$. Estradiol enhances cell proliferation and provokes cell cycle progression (96). The inhibitory effect of melatonin (as occurs for tamoxifen) on cell proliferation is cell-cycle specific, causing the presence of melatonin a delay in the $\mathrm{G}_{1}-\mathrm{S}$ transition (97). Changes in cell-cycle timing typically implicate modifications in various key proteins that regulate the process. The inhibitory action of the pineal hormone on cell cycle progression can be interpreted through its effects on the expression of certain proteins controlling the $\mathrm{G}_{1}-\mathrm{S}$ cell cycle transition. Thus, several studies have demonstrated that melatonin increases the expression of p53 and p $21^{\text {Waf1 }}$ in experiments performed in vitro $(98,99)$. The upregulation of these proteins may be a crucial mechanism explaining how melatonin impedes the progression through the cell cycle at the $\mathrm{G}_{1}-\mathrm{S}$ transition. The accumulation of cells in $\mathrm{G}_{1}$ forces them to enter $G_{0}$, causing the cancer cells to undergo a higher differentiation, since $G_{0}$ is characterized to be a quiescent state (100). This suggest that the anti-estrogenic, oncostatic and antiproliferative effects of melatonin on human mammary cancer estrogen-positive cell lines may be explained, at least in part, by the ability of the pineal hormone to inhibit cell proliferation at the same time that it enhances cell differentiation. Furthermore, several studies have demonstrated that melatonin inhibits human telomerase reverse transcriptase, which is the rate-limiting factor conditioning the telomerase activity in breast cancer cells $(101,102)$.

Another effect of melatonin in MCF-7 cells is its ability to reduce their invasiveness $(103,104)$. Melatonin treatment decreases the attachment of the cells to the basement membrane (105). The pineal hormone reduces the chemotactic response of MCF-7 cells (105). Melatonin also blocks the cell migration and invasion that occurs in response to estradiol (105). Cancer cells' motility and invasion are known for being adhesion-dependent mechanisms that require the expression of cell-surface molecules necessary for adhesion (106). In tumor progression, downregulation or loss of expression of several of these surface-adhesion proteins frequently happens, which leads to the loss of cell-cell recognition and the acquisition of an invasive phenotype by the tumor cells; these events correlate with poor cell differentiation (107). All the factors mentioned above are associated with poor prognosis in cancer progression (108). Importantly, among the melatonin antitumor actions, it has been reported that melatonin induces the expression of both $\beta_{1}$-integrin and E-cadherin, two main proteins essential for cell-cell and cell-matrix interactions; thus, melatonin changes estrogen-responsive tumor cells into a less invasive phenotype by inducing their differentiation (105).

Finally, melatonin exerts its modulatory effect in the tumor microenvironment by controlling the production and secretion of several cytokines. These cytokines are produced by breast cancer cells and regulate the differentiation of the fibroblasts located in close proximity to malignant epithelial cells. Additionally, it has been demonstrated that cytokines produced by malignant cells stimulate the aromatase expression and activity in these fibroblasts $(109,110)$ and in proximal endothelial cells (111). VEGF is a growth factor that serves an essential role in angiogenesis. VEGF is produced and secreted by malignant epithelial cells and recognizes VEGFRs located in the cell surface of endothelial cells. The binding of VEGF to its receptor triggers a cascade of intracellular events that stimulate endothelial cells to undergo proliferation and migration $(112,113)$. Therefore, pharmacological agents able to inhibit the production of this pro-angiogenic factor are of great interest, and could serve an essential role in impairing both tumor angiogenesis and tumor growth. Melatonin may be one molecule to consider, since it can regulate the paracrine mechanisms connecting tumor epithelial cells and the surrounding endothelial cells. One of the main actions of the pineal hormone is that melatonin treatment results in the downregulation of VEGF expression in estrogen-responsive breast cancer cells. As a result, the VEGF levels available for receptors expressed in endothelial cells are lower, and therefore, the number of cells producing estrogens in the proximity of the malignant cells is reduced. Reduced estrogen levels and a lower capability of formation of new vessels as a result of the presence of melatonin will diminish the tumor ability to spread and grow (114).

In summary, a unique molecule, melatonin, has anti-estrogenic properties: It selectively counterbalances the actions of estrogens in both normal and tumor breast tissues, and provides a novel strategy to reduce the local biosynthesis of estrogens from androgens (which in turn, is one of the principal objectives of antitumor pharmacological therapy) (115). These cumulative actions of the pineal hormone point to its potential application as an anticancer molecule in both the prevention and treatment of estrogen-positive tumors, since, as it has been pointed above, this molecule acts at different levels by 
interfering with estradiol-dependent signaling pathways, both in tumor cells and in the surrounding endothelial cells and fibroblasts (116).

\section{Melatonin and cancer: Clinical trials}

As aforementioned, numerous experiments performed in vitro (breast cancer cell lines such as MCF-7) and in vivo (animal models) have well established the oncostatic properties of melatonin (117). Since melatonin plasma levels are diminished in estrogen-dependent breast cancer patients, various clinical trials have been performed to evaluate the potential beneficial effects of melatonin in human neoplasms. Following the pioneer clinical work of Lissoni et al (118), who evaluated the effect of melatonin in cancer patients bearing untreatable advanced solid tumors, multiple studies have been performed and published to date (119). However, the value of melatonin as an adjuvant agent in cancer treatment is not totally clear, and consensus about positive melatonin actions appears to be difficult to achieve. A number of studies point to melatonin as a treatment with no beneficial effects. In cachectic patients with gastrointestinal or advanced lung cancer, including a dose of melatonin at night did not improve parameters such as appetite, weight or quality of life of patients, in comparison with patients who received a placebo (120). In patients with brain metastases, high doses of melatonin did not produce any beneficial effect (121). By contrast, there are a large number of reports supporting the potential benefits of melatonin if included in chemotherapy protocols. In breast, lung and gastrointestinal cancer patients, melatonin protected against thrombocytopenia, and stomatitis, asthenia and neuropathy were less recurrent in the group of melatonin-treated patients (122). It has also been reported that melatonin offers certain protection to hematopoietic progenitors from the toxic actions of anticancer chemotherapeutic chemicals; thus, melatonin has been reported to attenuate the damage to precursor blood cells caused by both radiotherapy and chemotherapy treatments (123). It has also been suggested that melatonin may protect patients against side effects such as asthenia, cardiotoxicity and neurotoxicity caused by chemotherapy (124). Additionally, the pineal hormone increases the 1-year survival and tumor regression rates in cancer patients with metastatic solid tumors with poor clinical status (125). In metastatic non-small cell lung cancer patients treated either with just chemotherapeutic agents or with chemotherapy plus melatonin, both the overall tumor regression rate and the 5-year survival rate of patients concomitantly receiving melatonin were significantly higher as compared with those receiving only chemotherapeutic agents. It appears that chemotherapy was better tolerated in patients who also received the pineal hormone (126). The study points to melatonin as an adjuvant drug capable of improving the effectiveness of chemotherapy in terms of both quality of life and survival of patients (126). A recent report concludes that melatonin combined with chemotherapy did not significantly improved survival or ameliorated various adverse side effects in patients with non-small cell lung advanced cancer, although certain improvement in the quality of life of these patients was observed (127). A systematic review comprising data from 21 clinical trials (all the patients enrolled in the studies were bearing solid tumors), in which the effect of melatonin concomitantly added in conjunction with chemotherapy or radiotherapy was evaluated, and supportive care, partial response, complete response, 1-year survival and chemotherapy-associated toxicities were assessed (128), concluded that melatonin may serve a beneficial role in cancer patients who are treated with chemotherapy. Patients who received melatonin experienced substantial improvements, particularly in terms of tumor remission and 1-year survival rates and melatonin also ameliorated the side effects of chemotherapy $(127,128)$. Furthermore, another review summarising the data from eight eligible randomized controlled trials $(n=761)$ obtained similar conclusions (129).

\section{Can melatonin enhance the beneficial and protect against the deleterious effects of chemotherapy?}

As aforementioned, it is well documented that melatonin diminishes the incidence of chemically induced cancers and is able to slow down the growth of certain hormone-responsive cancers $(67,117)$. The antitumor actions of this indolamine have been described in breast cancer, both in in vivo animal experiments (in 7,12-dimethylbenz[a]anthracene chemically induced mammary tumors in rodents) and in in vitro assays (in estrogen-positive human mammary cancer cell lines) (64). Furthermore, there are numerous reports endorsing the beneficial use of melatonin during chemotherapy in clinical trials $(118,122-124)$. Therefore, the ultimate goal of the present review is to provide a compilation on the current knowledge concerning the interplay of melatonin and chemotherapy agents at the molecular level. The PubMed database (www.ncbi.nlm.nih.gov/pubmed) was interrogated for citations of 84 genes known to be commonly involved in the dysregulation of several normal processes during breast carcinogenesis, which are also present in breast cancer cell lines. The list includes signal transduction genes and other genes involved in usually altered pathways, including cellular adhesion, angiogenesis, proteolytic activities, cell cycle progression, cell cycle control and apoptosis (Table I). Research into carcinogenic mechanisms (130) has identified during the last decades numerous functional alterations due to somatic mutations, gene expression alterations and altered post-translational protein modifications (131). Therefore, the database search was performed including as keywords i) the name of each gene, ii) breast cancer, iii) melatonin, and iv) chemotherapy.

For the majority of genes reviewed, there were thousands of citations in the literature when the search included the name of each gene and breast cancer as key words. When melatonin was included in the selection criteria, the number of articles was markedly reduced; thus, 53 out of the 84 genes surveyed did not have a single report associated under these criteria. Searching for ER together with melatonin and breast cancer led to $\sim 100$ articles, whereas p53 and PGR searches produced 15 and 12 reports respectively, and the rest of the 28 genes evaluated produced 1-9 articles.

The number of reports was further reduced if chemotherapy was also included in the selection criteria. Only 25 of the 84 genes assessed are included in the list (Table I), indicating that, for 59 out of 84 genes, there is not a single study published including the gene name, melatonin, breast cancer and chemotherapy as keywords. 
In Table II, a search was performed including as keywords melatonin (20,724 articles) melatonin and breast cancer (524 articles), and 28 drugs commonly used as chemotherapy in breast cancer treatment $(6,9)$. Apart from tamoxifen (23 articles fulfilled the criteria 'melatonin, breast cancer and tamoxifen'), the results show that there is limited information at the molecular level concerning the implication of co-treatment with the pineal indolamine and chemotherapy agents in breast cancer targeted therapy, and no report was available for 13 of the 28 drugs searched. In conclusion, despite the fact that during decades numerous articles have reported experimental data from in vitro and in vivo experiments showing the oncostatic actions of melatonin, the present review demonstrated that there are limited reports studying the effects of melatonin and chemotherapy agents in combination in cancer treatments, and particularly, in breast cancer. Similarly, little is known about the role of melatonin regarding the expression and functionality of the genes reported to be altered in cancer, particularly in breast cancer. There is little information available nowadays about gene expression profiles in all types of cancer, and particularly in estrogen-responsive breast tumors. There is also limited information available on how the gene expression profile may be altered by treatment with different chemotherapeutic compounds and, remarkably, whether or not melatonin has protective effects when administered together with chemotherapeutic agents. The majority of information available about melatonin, cancer, chemotherapy, and altered gene expression and function has been published $(132,133)$ in the last few years (Fig. 1). This indicates that nowadays there is a growing field of research about this topic. Several of the most relevant findings recently reported with regard to the modulatory role of melatonin in cancer at the molecular level include the circadian interruption of melatonin production by exposure to light at night, which results in the development of resistance to tamoxifen treatment in breast cancer patients (134). In this context, it has also been described how nocturnal disruption of melatonin plasma levels originates a complete loss of tumor response to the chemotherapeutic agent doxorubicin (135). The resistance of cancer cells to chemotherapy treatments such as doxorubicin usually implicates an upregulation of P-glycoprotein, which is responsible for drug efflux from cells (136). In this context, there is a report describing that melatonin treatment increases doxorubicin intracellular concentrations in cancer cells, suggesting that melatonin may inhibit P-glycoprotein (137). In breast cancer xenografts implanted in animal models (nude mice), treatment with the pineal hormone stopped the tumor progression by reducing tumor size and cell proliferation (Ki-67), as well as by inhibiting angiogenesis (138). Melatonin treatment results in increased expression of Bcl-2-like protein 11 (Bim) parallel to lower levels of cyclooxygenase (COX)-2, which in turns potentiate tunicamycin-induced apoptosis in mammary cancer cells (139). Regulation of the COX-2, Akt, p300 and apoptotic protease activating factor-1 signaling pathways by melatonin inhibits cell proliferation and triggers apoptosis in breast cancer cells in in vitro models (140). Melatonin also regulates mouse double minute 2 homolog (MDM2), since this indolamine strongly represses MDM2 gene expression and inhibits MDM2 translocation into the nucleus of the cells (141). This can be explained because melatonin stimulates ribosomal protein L11 and inhibits the phosphorylation of MDM2 by Akt-phosphatidylinositol-4,5-bisphosphate 3-kinase (141). Melatonin downregulates sirtuin, which is a specific inhibitor of p300, and upregulates p300 and murine double minute $\mathrm{X}$ (MDMX) (141). As a consequence, cells exposed to melatonin exhibit significantly increased levels of p53 and of its acetylated form (141). Finally, there is a significant increase in p21 levels in melatonin-treated tumor cells (141). It has been reported that melatonin sensitizes non-small cell lung cancer cells harboring a mutated form of EGFR to gefitinib (a tyrosine kinase inhibitor) (142). In combination with cisplatin, melatonin enhances the cytotoxic effects of this chemotherapeutic agent and promotes the entry into apoptosis of lung cancer cells (143) and cervical cancer-derived HeLa cells (144). Consistently with these findings, co-treatment with melatonin and each of the following three chemotherapy agents: Cisplatin, 5-fluorouracil and doxorubicin, resulted in an enhancement of cytotoxicity and apoptosis triggered by chemotherapy in the cell line AR42J, which is derived from rat pancreatic tumors (145). There is only one report addressing the effect of melatonin combined with the purine nucleoside antimetabolite clofarabine, describing that melatonin use as co-treatment led to an enhanced cytotoxic effect of clofarabine in leukemic cell lines, which was associated with higher levels of acetylation (146). In $\mathrm{ER}^{+}$breast cancer rat models treated with Adriamycin ${ }^{\circledR}$, melatonin co-treatment results in lighter tumor weights, increased tumor cell apoptosis, higher expression of E-cadherin and higher survival rate (147). In combination with the nucleoside analogue gemcitabine, recent reports demonstrate that melatonin inhibits both proliferation and invasion of pancreatic ductal adenocarcinoma cells through nuclear factor- $\kappa \mathrm{B}$ inhibition (148). Melatonin supports the effects of doxorubicin by activating transient receptor potential vanilloid 1 and apoptosis, thus inducing MCF-7 cell death (149). In a model of ovarian carcinoma, melatonin therapy promotes apoptosis along with the upregulation of $\mathrm{p} 53$, B-cell lymphoma ( $\mathrm{Bcl})-2$-associated $\mathrm{X}$ protein (Bax) and cleaved caspase-3, suggesting that melatonin triggers apoptosis in ovarian cancer cells (150). In a gastric cancer cell line (AGS), p38, c-Jun N-terminal kinase and extracellular signal-regulated kinase were activated by melatonin, which also significantly increased caspase- 3 activity, increased the expression of the pro-apoptotic gene Bax and decreased the expression of the anti-apoptotic gene Bcl-2 (151). Additionally, melatonin is able to strengthen the antitumor effects of cisplatin with low systemic toxicity (143).

\section{Conclusions}

Melatonin is a notable molecule to be considered in cancer treatment. A growing amount of evidence in the last few years has suggested that melatonin behaves as an oncostatic agent in a variety of cancer types in general, an in particularly, in hormone-dependent breast cancer, as documented from numerous studies performed either in animal models in vivo or in cell lines derived from human breast cancer in vitro $(64,67,81)$. Clinical trials suggest that melatonin can have protective effects when administered along with chemotherapy in patients suffering from advanced solid tumors (129). The mechanisms underlying the oncostatic actions of the pineal hormone in 
Table I. PubMed search results. ${ }^{\mathrm{a}}$

\begin{tabular}{|c|c|c|c|c|c|c|}
\hline $\begin{array}{l}\text { Gene } \\
\text { name }\end{array}$ & Gene $^{\mathrm{a}}$ & $\begin{array}{l}\text { Gene } \\
\text { AND } \\
\text { breast } \\
\text { cancer }\end{array}$ & $\begin{array}{c}\text { Gene } \\
\text { AND } \\
\text { melatonin }\end{array}$ & $\begin{array}{c}\text { Gene AND } \\
\text { breast } \\
\text { cancer } \\
\text { AND } \\
\text { melatonin }\end{array}$ & $\begin{array}{c}\text { Gene AND } \\
\text { breast cancer } \\
\text { AND } \\
\text { melatonin AND } \\
\text { chemotherapy }\end{array}$ & $\begin{array}{c}\text { Gene AND } \\
\text { cancer AND } \\
\text { melatonin AND } \\
\text { chemotherapy }\end{array}$ \\
\hline ER & 68,885 & 31,082 & 189 & 96 & 31 & 52 \\
\hline p53 & 78,342 & 7,698 & 80 & 15 & 7 & 12 \\
\hline $\mathrm{p} 21$ & 31,647 & 2,174 & 35 & 9 & 5 & 12 \\
\hline VEGF & 57,030 & 2,737 & 64 & 12 & 3 & 11 \\
\hline PGR & 33,762 & 13,582 & 73 & 96 & 3 & 5 \\
\hline TGFB1 & 22,043 & 561 & 25 & 4 & 3 & 4 \\
\hline MYC & 29,932 & 1,882 & 17 & 5 & 3 & 3 \\
\hline CDH1 & 23,363 & 2,200 & 13 & 5 & 3 & 3 \\
\hline IL6 & 96,419 & 1,106 & 162 & 3 & 2 & 10 \\
\hline GSTP1 & 35,897 & 901 & 91 & 2 & 2 & 7 \\
\hline c-JUN & 102,575 & 2,952 & 106 & 6 & 2 & 6 \\
\hline RARB & 11,545 & 651 & 76 & 9 & 2 & 5 \\
\hline CCND1 & 16,332 & 2,205 & 16 & 6 & 2 & 2 \\
\hline $\mathrm{AR}$ & 22,741 & 1,690 & 64 & 3 & 1 & 11 \\
\hline AKT & 54,018 & 3,992 & 92 & 6 & 1 & 10 \\
\hline Ki-67 & 20,827 & 3,129 & 18 & 5 & 1 & 5 \\
\hline ERK1 & 26,166 & 1,153 & 61 & 4 & 1 & 3 \\
\hline ERBB2 & 22,268 & 14,282 & 72 & 3 & 1 & 3 \\
\hline EGFR & 35,864 & 3,550 & 7 & 3 & 1 & 3 \\
\hline IGFBP3 & 5,003 & 432 & 6 & 2 & 1 & 2 \\
\hline EGF & 29,673 & 2,215 & 24 & 6 & 1 & 2 \\
\hline $\mathrm{Rb}$ & 19,405 & 1,017 & 16 & 1 & 1 & 1 \\
\hline IGF1 & 2,700 & 160 & 15 & 1 & 1 & 1 \\
\hline CDK2 & 6,054 & 491 & 5 & 1 & 1 & 1 \\
\hline p73 & 2,089 & 113 & 1 & 1 & 1 & 1 \\
\hline
\end{tabular}

${ }^{\mathrm{a}} \mathrm{A}$ search in PubMed database was performed for 84 genes known to be altered in breast cancer. The numbers refer to the citation found when the keywords used were: i) 'Gene name'; ii) 'gene name' AND 'breast cancer'; iii) 'gene name' AND 'melatonin'; iv) 'gene name' AND ‘breast cancer' AND 'melatonin'; v) 'gene name' AND 'breast cancer' AND 'melatonin' AND 'chemotherapy'; and vi) 'gene name' AND 'cancer' AND 'melatonin' AND 'chemotherapy'. In the table, only the 25 genes that appear at least in one publication with the criteria 'gene name' AND 'breast cancer' AND 'melatonin' AND 'chemotherapy' are shown. The genes that have appear in any publication under these criteria of search are gelatinase A, PTGS2, Bad, Bcl-2, BIRC5, gelatinase B, CTNNB1, APC, ASC, ATM, ABCB1, ABCG2, BRCA1, TFF3, cathepsin, $\mu$-PA, SRC, PAI-1, serpine 1, JNK1, IGF1R, CDKN2A, ADAM23, PTEN, NOTCH1, THBS1, ID1, keratin 5, GATA3. ERK2, CCNE1, XBP1, NR3C1, BRCA2, MUC1, MLH1, keratin 19, NME1, TWIST1, FOXA1, RASFF1, HIC1, SFN, MGMT, CCND2, cystatin, GRB7, keratin8, GLI1, keratin18, SFRP1, SNAI2, p57, cyclin A1, CDH13, CSF1, SLIT2, SLC39A6 and PRM2.

estrogen-dependent breast tumors are based on its behaviour as a SERM and SEEM, as well as on the ability of melatonin to influence the communication among malignant epithelial cells, endothelial cells and fibroblasts in breast cancer $(110,116)$. However, to date, there is limited knowledge about the interplays of melatonin and chemotherapy on molecular aspects such as gene expression profiles and gene post-translational modifications, which must be further addressed in the future.

\section{Melatonin and cancer: What next?}

Melatonin is a pleiotropic molecule that exerts numerous physiological functions and serves important roles in different processes, including circadian rhythm, sleep and reproduction (152). A particular characteristic of the pineal hormone is the diversity of molecular mechanisms that act to regulate the above physiological processes. Melatonin reduces cell proliferation and growth of estrogen-positive breast tumors by interfering with estrogen signaling pathways. Data obtained from experiments performed in breast cancer cell lines $(93,94)$ and animal models $(81,116)$ have provided evidence that melatonin diminishes the incidence of mammary tumors and limits their growth in vivo, and inhibits the proliferation of human breast cancer cell lines and interferes with their metastatic behaviour in vitro $(81,97)$. There are several proposed theories to explain the mechanisms by which melatonin reduces the growth and 
Table II. Number of publications identified in the MEDLINE (https://www.ncbi.nlm.nih.gov/pubmed) journal citation database (accessed November 2015), when using as search term each of the 28 molecules currently used in breast cancer research and/or treatment, alone (second column), including melatonin (third column) or including melatonin plus breast cancer (fourth column) as searching criteria.

\begin{tabular}{lrrr}
\hline & & & $\begin{array}{c}\text { Melatonin } \\
\text { AND }\end{array}$ \\
Drug name & $\begin{array}{r}\text { Drug } \\
\text { alone }\end{array}$ & Melatonin & $\begin{array}{c}\text { breast cancer } \\
\text { bincristine }\end{array}$ \\
\hline Eribulin & - & 20,724 & 524 \\
Paclitaxel & 27,607 & 10 & 0 \\
Docetaxel & 27,688 & 0 & 0 \\
Epirubicin & 11,691 & 3 & 2 \\
Lapatinib & 6,131 & 5 & 1 \\
Trastuzumab & 1,807 & 1 & 1 \\
Pazopanib & 7,382 & 2 & 0 \\
Bevacizumab & 825 & 0 & 0 \\
Fulvestrant & 11,697 & 6 & 0 \\
Anastrozole & 2,278 & 5 & 1 \\
Irosustat & 1,761 & 1 & 0 \\
Tanespicin & 46 & 0 & 0 \\
Cisplatin & 665 & 0 & 0 \\
Gemcitabine & 59,192 & 50 & 4 \\
Pitavastin & 12,035 & 6 & 1 \\
Pravastatin & 658 & 3 & 1 \\
Vinblastine & 4,318 & 1 & 1 \\
Cyclophos-phamide & 1,582 & 14 & 0 \\
Methotrexate & 64,488 & 63 & 8 \\
Fluorouracil & 45,411 & 20 & 4 \\
Adryamicin & 48,858 & 18 & 6 \\
Vinorelbine & 60,505 & 74 & 8 \\
Mitomycin & 3,472 & 2 & 0 \\
Capecitabine & 4,202 & 6 & 0 \\
Mitoxantrone & 5,536 & 1 & 0 \\
Carboplatin & 13,873 & 5 & 2 \\
Tamoxifen & 25,107 & 44 & 0 \\
\hline & & & 23 \\
\hline
\end{tabular}

development of tumors: i) Through an indirect mechanism, by downregulating the synthesis of estrogens via downregulation of the hypothalamic-pituitary-reproductive axis; ii) through a direct mechanism, by interfering with the activation of estradiol receptors at the cancer cell level, thus behaving as a SERM; and iii) melatonin can regulate the enzymes necessary for the synthesis of estrogens in other tissues, therefore behaving as a SEEM (79). It has been recently demonstrated that melatonin regulates the paracrine communication that occurs between malignant epithelial cancer cells, the surrounding adipose tissue (fibroblasts and adipocytes) and endothelial cells, mainly through the downregulation of the levels of growth factors and cytokines released by breast tumor cells (116). Thus, the effects of melatonin also include anti-angiogenic actions.

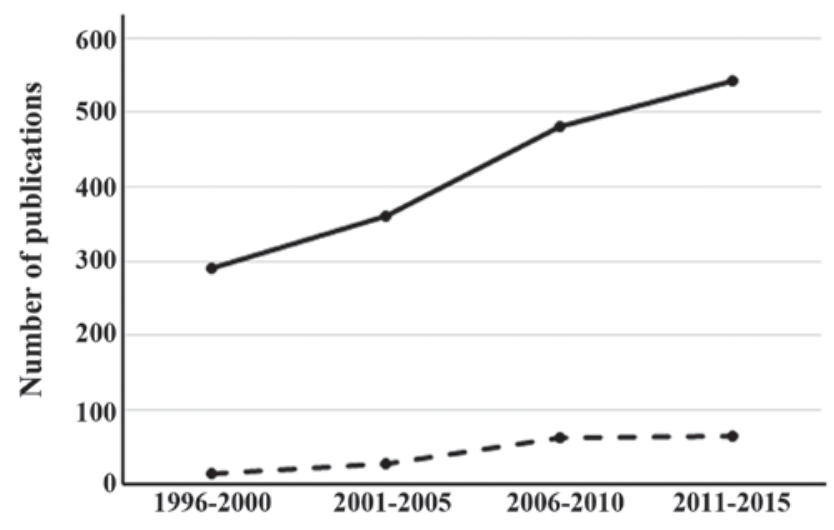

Figure 1. Number of publications regarding melatonin and cancer (solid line), and melatonin, cancer and gene expression (dotted line) published during the last two decades.

In summary, previous studies point to melatonin as a molecule that has a great potential to be useful as an anticancer chemical without producing adverse effects (128). Therefore, melatonin should be considered for both the prevention and therapy of estrogen-positive mammary tumors. There are, in our opinion, numerous noteworthy possibilities for future clinical applications of melatonin in several types of cancer, including breast cancer.

Recently, the inhibitory effects of melatonin have been described not only for estrogen-dependent breast tumors, but also for numerous different cancers, including gastric cancer, ovarian carcinoma, pancreatic ductal carcinoma, leukemic cell lines, cervical cancer and non-small lung carcinoma cells $(25,137-139,142,143,153)$. The majority of the results are positive, and melatonin has been described as an inhibitor of tumor growth under both in vitro and in vivo experimental conditions $(64,81,97)$. The results arisen in the past few years also suggest that melatonin, either alone or along with chemotherapy in cancer patients diagnosed with advanced solid tumors, helps to improve the outcomes of cancer regression and life expectancy of the patients $(122,128)$. Additionally, chemotherapies are typically better tolerated by patients who are simultaneously treated with melatonin (125). Following the pioneer clinical study of melatonin potential positive effects in untreatable advanced cancer patients performed by Lissoni et al (118) several studies have been published (124-129). The main limitation is the requirement of further studies, including additional randomized double-blind controlled trials with much larger sample sizes and implicating several international hospital centres, since the data available nowadays derive from clinical trials including only a few hundred patients (128). Furthermore, it must be considered that not all the studies performed to date point to melatonin as a molecule that improves life expectancy and ameliorates the adverse effects of chemotherapy $(120,121)$. Thus, in patients with advanced lung or gastrointestinal cancer, melatonin did not exhibit any beneficial effect, and as consequence, the value of melatonin as an adjuvant in the treatment of cancer remains unclear from these data (120).

One of the main objectives of the present review was to summarise the current knowledge regarding the interplay of melatonin and chemotherapy. Since the majority of the potentially beneficial effects of melatonin have been described in 
estrogen-responsive breast cancer, the present study searched information published on 84 genes known to be dysregulated during breast carcinogenesis (corresponding to the genes included in The Human Breast Cancer RT2 ${ }^{2}$ Profiler PCR array; Qiagen GmbH, Hilden, Germany). These genes encode proteins implicated in signal transduction, angiogenesis, proteolysis, cell cycle and apoptosis (154).

The present study also reviewed recently published articles associating melatonin with chemotherapeutic agents (135-137,142-149). The results indicate that, for 53 out of the 84 genes evaluated, there are no current data available regarding the effect of melatonin alone or in combination with chemotherapy, either in in vivo or in in vitro studies. Our findings also show that, apart from tamoxifen, there is limited information from research performed at the molecular level addressing the potential benefits of co-treatment of melatonin with chemotherapeutic agents (155).

In summary, in our opinion, melatonin is an endogenous produced hormone with a high potential of being included as an effective anticancer molecule in the prevention and treatment of, not only hormone-dependent cancers, but also, other types of cancer, since its inhibitory effects have been demonstrated in gastric, lung, pancreatic and hematopoietic cancers $(145,148,151,153)$. However, in the next years, additional research must be conducted to clarify if melatonin administration in combination with chemotherapeutic agents may constitute a novel anticancer treatment. In particular, future research concerning the role of melatonin as a non-toxic and low-cost drug to be considered in breast and other types of tumors must be conducted, particularly at the molecular level. Systematic screenings addressing the effects of chemotherapy on genes known to be altered in different types of cancer, and on how melatonin can modulate the expression and activity of those genes, either when acting alone or in combination with chemotherapy, should be performed. Once larger clinical trials and additional molecular studies (including gene expression profiles, post-translational modifications and individual gene tests) have been conducted, it may be reasonable to recommend melatonin as a potential drug to be considered in the treatment of breast cancer.

\section{Acknowledgements}

The present study was supported by grants from the Spanish Science Technology and Innovation Ministry (grants no. SAF2013-42012-P, SAF2016-77103-P) and the Research Institute Valdecilla (grant no. APG/12).

\section{References}

1. World Cancer Research Fund/American Institute for Cancer Research: Second Expert Report. http://www.wcrf.org/int/ research-we-fund/continuous-update-project-cup/second-expertreport. Accessed August 14, 2016.

2. American Cancer Society: Cancer facts and figures 2015. http://www.cancer.org/research/cancerfactsstatistics/cancerfactsfigures2015. Accessed August 14, 2016.

3. American Cancer Society: What are the key statistics about breast cancer? http://www.cancer.org/cancer/breastcancer/ detailedguide/breast- cancer-key-statistics. Accessed August 14, 2016.

4. Reynolds T: Declining breast cancer mortality: What's behind it? J Natl Cancer Inst 91: 750-753, 1999.
5. Rossouw JE, Anderson GL, Prentice RL, LaCroix AZ, Kooperberg C, Stefanick ML, Jackson RD, Beresford SA, Howard BV; Writing Group for the Women's Health Initiative Investigators, et al: Risks and benefits of estrogens plus progestin in healthy postmenopausal women. Principal results from the Women's Health Initiative Randomized Controlled trial. J Am Med Assoc 288: 321-333, 2002.

6. Greig RG and Trainer DL: Shaping future strategies for the pharmacological control of tumor cell metastases. Cancer Metastasis Rev 5: 3-14, 1986.

7. Perloff M and Holland JF: Surgical adjuvant chemotherapy. Ann Rev Med 28: 475-488, 1977.

8. Maughan KL, Lutterbie MA and Ham PS: Treatment of breast cancer. Am Fam Physician 81: 1339-1346, 2010.

9. Mamounas EP: Impact of neoadjuvant chemotherapy on locoregional surgical treatment of breast cancer. Ann Surg Oncol 22: 1425-1433, 2015.

10. Masood S: Neoadjuvant chemotherapy in breast cancers. Womens Health (Lond) 12: 480-491, 2016.

11. Suter R and Marcum JA: The molecular genetics of breast cancer and targeted therapy. Biologics 1: 241-258, 2007.

12. BreastCancer.Org. How is Chemotherapy Given? http://www. breastcancer.org/treatment/chemotherapy/process/how.Accessed August 14, 2016.

13. Jordan MA and Wilson L: Microtubules as a target for anticancer drugs. Nat Rev Cancer 4: 253-265, 2004.

14. Moudi M, Go R, Yien CY and Nazre M: Vinca alcaloids. Int J Prev Med 4: 1231-1235, 2013.

15. Johnson IS, Armstrong JG, Gorman M and Burnett JP Jr: The Vinca Alkaloids: A new class of oncolytic agents, Cancer Res 23: 1390-1427, 1963.

16. Himes RH: Interactions of the catharanthus (Vinca) alkaloids with tubulin and microtubules. Pharmacol Ther 51: 257-267, 1991.

17. Gigant B, Wang C, Ravelli RB, Roussi F, Steinmetz MO, Curmi PA, Sobel A and Knossow M: Structural basis for the regulation of tubulin by vinblastine. Nature 435: 519-522, 2005.

18. Graf E and Bertholdt H: Amorphous taxine \& crystalline taxine A; Taxus alkaloids. II. Pharm Zentralhalle Dtschl 96: 385-395, 1957 (In German)

19. Wani MC, Taylor HL, Wall ME, Coggon P and McPhail AT: Plant antitumor agentes. VI. The isolation and structure of taxol, a novel antileukemic and antitumor agente from Taxus brevifolia. J Am Chem Soc 93: 2325-2327, 1971.

20. Wiernik PH, Schwartz EL, Strauman JJ, Dutcher JP, Lipton RB and Paietta E: Phase I clinical and pharmacokinetic study of taxol. Cancer Res 47: 2486-2493, 1987.

21. Bissery MC, Guénard D, Guéritte-Voegelein F and Lavelle F: Experimental antitumor activity of Taxotere (RP 56976 , NSC 628503), a taxol analogue. Cancer Res 51: 4845-4852, 1991.

22. Ringel I and Horwitz SB: Studies with RP 56976 (Taxotere): A semisynthetic analogue of taxol. J Natl Cancer Inst 83: 288-291, 1991.

23. Xiao H, Verdier-Pinard P, Fernandez-Fuentes N, Burd B, Angeletti R, Fiser A, Horwitz SB and Orr GA: Insights into the mechanism of microtubule stabilization by Taxol. Proc Natl Acad Sci USA 103: 10166-10173, 2006.

24. Snyder JP, Nettles JH, Cornet B, Downing KH and Nogales E: The binding conformation of Taxol in beta-tubulin: A model based on electron crystallographic density. Proc Natl Acad Sci USA 98: 5312-5316, 2001.

25. Jain KK, Casper ES, Geller NL, Hakes TB, Kaufman RJ, Currie V, Schwartz W, Cassidy C, Petroni GR, Young CW, et al: A prospective randomized comparison of epirubicin and doxorubicin in patients with advanced breast cancer. J Clin Oncol 3: 818-826, 1985.

26. Mizuno NS, Zakis B and Decker RW: Binding of daunomycin to DNA and the inhibition of RNA and DNA synthesis. Cancer Res 35: 1542-1546, 1975.

27. Andoh T: Inhibitors of DNA topoisomerases. Gan To Kagaku Ryoho 24: 1526-1535, 1997 (In Japanese).

28. Khasraw M, Bell R and Dang C: Epirubicin: Is it like doxorubicin in breast cancer? A clinical review. Breast 21: 142-149, 2012.

29. US Food and Drug Administration. Advisory Committees: 2010 Meeting Materials, Oncologic Drugs Advisory Committee. http://www.cancer.gov/about-cancer/treatment/drugs/fda-eribulinmesylate. Accessed November 28, 2016

30. Towle MJ, Salvato KA, Wels BF, Aalfs KK,Zheng W, Seletsky BM, Zhu X, Lewis BM, Kishi Y, Yu MJ and Littlefield BA: Eribulin induces irreversible mitotic blockade: Implications of cell-based pharmacodynamics for in vivo efficacy under intermittent dosing conditions. Cancer Res 71: 496-505, 2011. 
31. Marhold M, Bartsch R and Zielinski C: Recent developments and translational aspects in targeted therapy for metastatic breast cancer. ESMO Open 1: e000036, 2016.

32. Wong WM: Drug update: Trastuzumab: Anti-HER2 antibody for treatment of metastatic breast cancer. Cancer Pract 7: 48-50, 1999.

33. Pegram MD, Lipton A, Hayes DF, Weber BL, Baselga JM, Tripathy D, Baly D, Baughman SA, Twaddell T, Glaspy JA and Slamon DJ: Phase II study of receptor-enhanced chemosensitivity using recombinant humanized anti-p185HER $2 /$ neu monoclonal antibody plus cisplatin in patients with HER $2 /$ neu-overexpressing metastatic breast cancer refractory to chemotherapy treatment. J Clin Oncol 16: 2659-2671, 1998.

34. Mayer IA: Treatment of HER2-positive metastatic breast cancer following initial progression. Clin Breast Cancer 9 (Suppl 2): S50-S57, 2009.

35. Kaufman B, Trudeau M, Awada A, Blackwell K, Bachelot T, Salazar V, DeSilvio M, Westlund R, Zaks T, Spector N and Johnston S: Lapatinib monotherapy in patients with HER2-overexpressing relapsed or refractory inflammatory breast cancer: Final results and survival of the expanded HER2+ cohort in EGR103009, a phase II study. Lancet Oncol 10: 581-588, 2009

36. Gomez HL, Doval DC, Chavez MA, Ang PC, Aziz Z, Nag S, $\mathrm{Ng} \mathrm{C}$, Franco SX, Chow LW, Arbushites MC, et al: Efficacy and safety of lapatinib as first-line therapy for ErbB2-amplified locally advanced or metastatic breast cancer. J Clin Oncol 26 2999-3005, 2008.

37. Burris HA III: Dual kinase inhibition in the treatment of breast cancer: Initial experience with the EGFR/ErbB-2 inhibitor lapatinib. Oncologist 9 (Suppl 3): S10-S15, 2004.

38. Burstein HJ, Sun Y, Dirix LI, Jiang Z, Paridaens R, Tan AR, Awada A, Ranade A, Jiao S, Schwartz G, et al: Neratinib, an irreversible ErbB receptor tyrosine kinase inhibitor, in patients with advanced ErbB2-positive breast cancer. J Clin Oncol 28 1301-1307, 2010

39. Rabindran SK, Discafani CM, Rosfjord EC, Baxter M, Floyd MB, Golas J, Hallett WA, Johnson BD, Nilakantan R, Overbeek E, et al: Antitumor activity of HKI-272, an orally active, irreversible inhibitor of the HER-2 tyrosine kinase. Cancer Res 64: 3958-3965, 2004.

40. Darby JF and Workman P: Chemical biology: Many faces of a cancer-supporting protein. Nature 478: 334-335, 2011.

41. Hague A, Alam Q, Alam MZ, Azhar EI, Sait KH, Anfinan N, Mushtaq G, Kamal MA and Rasool M: Current understanding of HSP90 as a novel therapeutic target: An emerging approach for the treatment of cancer. Curr Pharm Des 22: 2947-2959, 2016.

42. Zsebik B, Citri A, Isola J, Yarden Y, Szöllosi J and Vereb G: Hsp90 inhibitor 17-AAG reduces ErbB2 levels and inhibits proliferation of the trastuzumab resistant breast tumor cell line JIMT-1. Immunol Lett 104: 146-155, 2006.

43. Beliakoff $\mathbf{J}$ and Whitesell L: Hsp90: An emerging target for breast cancer therapy. Anticancer Drugs 15: 651-662, 2004.

44. McDonald PC, Chafe SC and Dedhar S: Overcoming hypoxia-mediated tumor progression: Combinatorial approaches targeting $\mathrm{pH}$ regulation, angiogenesis and immune dysfunction. Front Cell Dev Biol 4: 27, 2016.

45. Rao N, Lee YE and Ge R: Novel endogenous angiogenesis inhibitors and their therapeutic potential. Acta Pharmacol Sin 36 $1177-1190,2015$

46. Arjaans M, Schröder CP, Oosting SF, Dafni U, Kleibeuker JE and de Vries EG: VEGF pathway targeting agents, vessel normalization and tumor drug uptake: From bench to bedside. Oncotarget 7: 21247-21258, 2016.

47. Kerbel RS: Strategies for improving the clinical benefit of antiangiogenic drug based therapies for breast cancer. J Mammary Gland Biol Neoplasia 17: 229-239, 2012

48. Kerr DJ: Targeting angiogenesis in cancer: Clinical development of bevacizumab. Nat Clin Pract Oncol 1: 39-43, 2004.

49. Mackey JR, Kerbel RS, Gelmon KA, McLeod DM, Chia SK, Rayson D, Verma S, Collins LL, Paterson AH, Robidoux A and Pritchard KI: Controlling angiogenesis in breast cancer: A systematic review of anti-angiogenic trials, Cancer Treat Rev 38 : 673-688, 2012

50. Miller KD, Chap LI, Holmes FA, Cobleigh MA, Marcom PK, Fehrenbacher L, Dickler M, Overmoyer BA, Reimann JD, Sing AP, et al: Randomized phase III trial of capecitabine compared with bevacizumab plus capecitabine in patients with previously treated metastatic breast cancer. J Clin Oncol 23: 792-799, 2005
51. Sloan B and Scheinfeld NS: Pazopanib, a VEGF receptor tyrosine kinase inhibitor for cancer therapy. Curr Opin Investig Drugs 9: 1324-1335, 2008

52. Gril B, Palmieri D, Qian Y, Smart D, Ileva L, Liewehr DJ, Steinberg SM and Steeg PS: Pazopanib reveals a role for tumor cell B-Raf in the prevention of HER2+ breast cancer brain metastasis. Clin Cancer Res 17: 142-153, 2011.

53. Taylor SK, Chia S, Dent S, Clemons M, Agulnik M, Grenci P, Wang L, Oza AM, Ivy P, Pritchard KI and Leighl NB: A phase II study of pazopanib in patients with recurrent or metastatic invasive breast carcinoma: A trial of the princess Margaret Hospital phase II consortium. Oncologist 15: 810-818, 2010.

54. Mauvais-Jarvis P, Kuttenn F and Gompel A: Estradiol/progesterone interaction in normal and pathological breast cells. Ann N Acad Sci 464: 152-167, 1986.

55. Lumachi F, Santeufemia DA and Basso SM: Current medical treatment of estrogen receptor-positive breast-cancer. World J Biol Chem 6: 231-239, 2015.

56. Ellis AJ, Hendrick VM, Williams R and Komm BS: Selective estrogen receptor modulators in clinical practice: A safety overview. Expert Opin Drug Saf 14: 921-934, 2015.

57. Jordan VC: Tamoxifen as the first targeted long-term adjuvant therapy for breast cancer. Endocr Relat Cancer 21: R235-R246, 2014

58. Dalmau E, Armengol-Alonso A, Muñoz M and Seguí-PalmerMÁ: Current status of hormone therapy in patients with hormone receptor positive $(\mathrm{HR}+)$ advanced breast cancer. Breast 23: 710-720, 2014

59. Morris C and Wakeling A: Fulvestrant ('Faslodex')-a new treatment option for patients progressing on prior endocrine therapy. Endocr Relat Cancer 9: 267-276, 2002

60. Johnston SJ and Cheung KL: Fulvestrant-a novel endocrine therapy for breast cancer. Curr Med Chem 17: 902-914, 2010.

61. Wong ZW and Ellis MJ: First-line endocrine treatment of breast cancer: Aromatase inhibitor or antioestrogen? Br J Cancer 90: 20-25, 2004.

62. Reiter RJ, Tan DX and Fuentes-Broto L: Melatonin: A multitasking molecule. Prog Brain Res 181: 127-151, 2010.

63. Reiter RJ, Tan DX and Galano A: Melatonin: Exceeding expectations. Physiology (Bethesda) 29: 325-333, 2014.

64. Hill SM, Belancio VP, Dauchy RT, Xiang S, Brimer S, Mao L, Hauch A, Lundberg PW, Summers W, Yuan L, et al: Melatonin: An inhibitor of breast cancer. Endocr Relat Cancer 22: R183-R204, 2015.

65. Dai J, Ram PT, Yuan L, Spriggs LL and Hill SM: Transcriptional repression of RORalpha activity in human breast cancer cells by melatonin. Mol Cell Endocrinol 176: 111-120, 2001.

66. Reiter RJ, Tan DX, Manchester LC, Lopez-Burillo S, Sainz RM and Mayo JC: Melatonin: Detoxification of oxygen and nitrogen-based toxic reactants. Adv Exp Med Biol 527: 539-548, 2003.

67. Blask DE, Pelletier DB, Hill SM, Lemus-Wilson A, Grosso DS, Wilson ST and Wise ME: Pineal melatonin inhibition of tumor promotion in the $\mathrm{N}$-nitroso-N-methylurea model of mammary carcinogenesis: Potential involvement of antiestrogenic mechanisms in vivo. J Cancer Res Clin Oncol 117: 526-532, 1991.

68. Tamarkin L, Almeida OF and Danforth DN Jr: Melatonin and malignant disease. Ciba Found Symp 117: 284-299, 1985.

69. Coleman MP and Reiter RJ: Breast cancer, blindness and melatonin. Eur J Cancer 28: 501-503, 1992.

70. Kliukiene J, Tynes T and Andersen A: Risk of breast cancer among norwegian women with visual impairment. $\mathrm{Br} \mathrm{J}$ Cancer 84: 397-399, 2001

71. Flynn-Evans EE, Stevens RG, Tabandeth H, Schernhammer ES and Lockey SW: Total visual blindness is protective against breast cancer. Cancer Causes Control 20: 1753-1756, 2009.

72. Schernhammer ES, Laden F, Speizer FE, Willet WC, Hunter DJ, Kawachi I and Colditz GA: Rotating night shifts and risk of breast cancer in women participating in the nurses' health study. J Natl Cancer Inst 93: 1563-1568, 2001.

73. González A, Cos S, Martínez-Campa C, Alonso-González C, Sánchez-Mateos S, Mediavilla MD and Sánchez-Barceló EJ: Selective estrogen enzyme modulator actions of melatonin in human breast cancer cells. J Pineal Res 45: 86-92, 2008.

74. Cos S, González A, Martínez-Campa C, Mediavilla MD, Alonso-González C and Sánchez-Barceló EJ: Estrogen-signaling pathway: A link between breast cancer and melatonin oncostatic actions. Cancer Detect Prev 30: 118-128, 2006.

75. Martínez-Campa C, González A, Mediavilla MD, Alonso-González C, Sánchez-Barceló EJ and Cos S: Melatonin enhances the inhibitory effect of aminoglutethimide on aromatase activity in MCF-7 human breast cancer cells. Breast Cancer Rse Treat 94: 249-254, 2005. 
76. Cos S,Martínez-Campa C,Mediavilla MDandSánchez-BarcelóEJ: Melatonin modulates aromatase activity in MCF-7 human breast cancer cells. J Pineal Res 38: 136-142, 2005.

77. Purohit A, Woo LW and Potter BV: Steroid sulfatase: A pivotal player in estrogen synthesis and metabolism. Mol Cell Endocrinol 340: 154-160, 2011

78. Sasano H, Suzuki T, Nakata T and Moriya T: New development in intracrinology of breast carcinoma. Breast Cancer 13: 129-136, 2006.

79. Cos S, González A, Martínez-Campa C, Mediavilla MD, Alonso-González C and Sánchez-Barceló EJ: Melatonin as a selective estrogen enzyme modulator. Curr Cancer Drug Targets 8: 691-702, 2008.

80. Álvarez-García V, González A, Martínez-Campa C, Alonso-González C and Cos S: Melatonin modulates aromatase activity and expression in endothelial cells. Oncol Rep 29: 2058-2064, 2013.

81. González A, Alvarez-García V, Martínez-Campa C, Mediavilla MD, Alonso-González C, Sánchez-Barceló EJ and Cos S: In vivo inhibition of the estrogen sulfatase enzyme and growth of DMBA-induced mammary tumors by melatonin. Curr Cancer Drug Targets 10: 279-286, 2010.

82. González A, Martínez-Campa C, Alonso-González C and Cos S: Melatonin affects the dynamic steady-state equilibrium of estrogen sulfates in human umbilical vein endothelial cells by regulating the balance between estrogen sulfatase and sulfotransferase. Int J Mol Med 36: 1671-1676, 2015.

83. Sánchez-Barceló EJ, Cos S, Mediavilla D, Martínez-Campa C, González A and Alonso-González C: Melatonin-estrogen interactions in breast cancer. J Pineal Res 38: 217-222, 2005.

84. García Pedrero JM,Del Río B, Martínez-Campa C, Muramatsu M, Lazo PS and Ramos S: Calmodulin is a selective modulator of estrogen receptors. Mol Endocrinol 16: 947-960, 2002.

85. Molis TM, Spriggs LL and Hill SM: Modulation of estrogen receptor mRNA expression by melatonin in MCF-7 human breast cancer cells. Mol Endocrinol 8: 1681-1690, 1994.

86. Rato AG, Pedrero JG, Martínez MA, del Río B, Lazo PS and Ramos S: Melatonin blocks the activation of estrogen receptor for DNA binding. FASEB J 13: 857-868, 1999

87. Bouhoute A and Leclercq G: Calmodulin decreases the estrogen binding capacity of the estrogen receptor. Biochem Bioph Res Commun 227: 651-657, 1996.

88. del Río B, García Pedrero JM, Martínez-Campa C, Zuazua P, Lazo PS and Ramos S: Melatonin, an endogenous-specific inhibitor of estrogen receptor alpha via calmodulin. J Biol Chem 279: 38294-38302, 2004.

89. Ram PT, Dai J, Yuan L, Dong C, Kiefer TL, Lai L and Hill SM: Involvement of the mtl melatonin receptor in human breast cancer. Cancer Lett 179: 141-150, 2002

90. Dillon DC, Easley SE, Asch BB, Cheney RT, Brydon L, Jockers R, Winston JS, Brooks JS, Hurd T and Asch HL: Differential expression of high-affinity melatonin receptors (MT1) in normal and malignant human breast tissue. Am J Clin Pathol 118: 451-458, 2002.

91. Aronica SM, Kraus WL and Katzenellenbogen BS: Estrogen action via the cAMP signaling pathway: Stimulation of adenylate cyclase and cAMP-regulated gene transcription. Proc Natl Acad Sci USA 91: 8517-8521, 1994.

92. Godson C and Reppert SM: The Mel1a melatonin receptor is coupled to parallel signal transduction pathways. Endocrinology 138: 397-404, 1997.

93. Hill SM, Spriggs LL, Simon MA, Muraoka H and Blask DE: The growth inhibitory action of melatonin on human breast cancer cells is linked to the estrogen response system. Cancer Lett 64: 249-256, 1992

94. Cos S and Blask DE: Melatonin modulates growth factor activity in MCF-7 human breast cancer cells. J Pineal Res 17: 25-32, 1994.

95. Molis TM, Spriggs LL, Jupiter Y and Hill SM: Melatonin modulation of estrogen-regulated proteins, growth factors, and proto-oncogenes in human breast cancer. J Pineal Res 18: 93-103, 1995.

96. Hong J, Shah NN, Thomas TJ, Gallo MA, Yurkow EJ and Thomas T: Differential effects of estradiol and its analogs on cyclin D1 and CDK4 expression in estrogen receptor positive MCF-7 and estrogen receptor-transfected MCF-10AEwt5 cells. Oncol Rep 5: 1025-1033, 1998.

97. Cos S, Blask DE, Lemus-Wilson A and Hill AB: Effects of melatonin on the cell kinetics and 'estrogen-rescue' of MCF-7 human breast cancer cells in culture. J Pineal Res 10: 36-42, 1991.
98. Mediavilla MD, Cos S and Sánchez-Barceló EJ: Melatonin increases p53 and p21WAF1 expression in MCF-7 human breast cancer cells in vitro. Life Sci 65: 415-420, 1999.

99. Alonso-González C, González A, Martínez-Campa C, Menéndez-Menéndez J, Gómez-Arozamena J, García-Vidal A and Cos S: Melatonin enhancement of the radiosensitivity of human breast cancer cells is associated with the modulation of proteins involved in estrogen biosynthesis. Cancer Lett 370 145-152, 2016

100. Wang SC, Lin SH, Su LK and Hung MC: Changes in BRCA2 expression during progression of the cell cycle. Biochem Biophys Res Commun 234: 247-251, 1997.

101. Leon-Blanco MM, Guerrero JM, Reiter RJ, Calvo JR and Pozo D: Melatonin inhibits telomerase activity in the MCF-7 tumor cell line both in vivo and in vitro. J Pineal Res 35: 204-211, 2003.

102. Martínez-Campa CM, Alonso-González C, Mediavilla MD, Cos S, González A and Sánchez-Barceló EJ: Melatonin down-regulates hTERT expression induced by either natural estrogens (17beta-estradiol) or metalloestrogens (cadmium) in MCF-7 human breast cancer cells. Cancer Lett 268: 272-277, 2008.

103. Alonso-González C, Mediavilla D, Martínez-Campa C, González A, Cos S and Sánchez-Barceló EJ: Melatonin modulates the cadmium-induced expression of MT-2 and MT-1 metallothioneins in three lines of human tumor cells (MCF-7, MDA-MB-231 and HeLa). Toxicol Lett 181: 190-195, 2008.

104. Mao L, Yuan L, Slakey LM, Jones FE, Burow ME and Hill SM Inhibition of breast cancer cell invasion by melatonin is mediated through regulation of the p38 mitogen-activated protein kinase signaling pathway. Breast Cancer Res 12: R107, 2010.

105. Cos S, Fernández R, Güezmes A and Sánchez-Barceló EJ: Influence of melatonin on invasive and metastatic properties of MCF-7 human breast cancer cells. Cancer Res 58: 4383-4390, 1998.

106. Kawaguchi T: Cancer metastasis: Characterization and identification of the behavior of metastatic tumor cells and the cell adhesion molecules, including carbohydrates. Curr Drug Targets Cardiovasc Haematol Disord 5: 39-64, 2005

107. Canel M, Serrels A, Frame MC and Brunton VG E-cadherin-integrin crosstalk in cancer invasion and metastasis. J Cell Sci 126: 393-401, 2013.

108. Gui GP, Puddefoot JR, Vinson GP, Wells CA and Carpenter R Altered cell-matrix contact: A prerequisite for breast cancer metastasis? Br J Cancer 75: 623-633, 1997.

109. González A, Alvarez-García V, Martínez-Campa C, Alonso-González C and Cos S: Melatonin promotes differentiation of 3T3-L1 fibroblasts. J Pineal Res 52: 12-20, 2012.

110. Alvarez-García V, González A, Alonso-González C, Martínez-Campa C and Cos S: Melatonin interferes in the desmoplastic reaction in breast cancer by regulating cytokine production. J Pineal Res 52: 282-290, 2012.

111. Alvarez-García V, González A, Alonso-González C, Martínez-Campa C and Cos S. Regulation of vascular endothelial growth factor by melatonin in human breast cancer cells. J Pineal Res 54: 373-380, 2013.

112. Gingis-Velitski S, Zetser A, Flugelman MY, Vlodavsky I and Ilan N: Heparanase induces endothelial cell migration via protein kinase B/Akt activation. J Biol Chem 279: 23536-23541, 2004.

113. Gu Q, Wang D, Wang X, Peng R, Liu J, Jiang T, Wang Z, Wang $S$ and Deng H: Basic fibroblast growth factor inhibits radiation-induced apoptosis of HUVECs. I. The PI3K/AKT pathway and induction of phosphorylation of BAD. Radiat Res 161: 692-702, 2004.

114. Alvarez-García V, González A, Alonso-González C, Martínez-Campa C and Cos S: Antiangiogenic effects of melatonin in endothelial cell cultures. Microvasc Res 87: 25-33, 2013.

115. Ahmad I and Shagufta: Recent developments in steroidal and nonsteroidal aromatase inhibitors for the chemoprevention of estrogen-dependent breast cancer. Eur J Med Chem 102: 375-386, 2015

116. Cos S, Álvarez-García V, González A, Alonso-González C and Martínez-Campa C: Melatonin modulation of crosstalk among malignant epithelial, endothelial and adipose cells in breast cancer (Review). Oncol Lett 8: 487-492, 2014.

117. Proietti S, Cucina A, Reiter RJ and Bizarri M: Molecular mechanisms of melatonin's inhibitory actions on breast cancers. Cell Mol Life Sci 70: 2139-2157, 2013. 
118. Lissoni P, Barni S, Tancini G, Crispino S, Paolorossi F, Lucini V, Mariani M, Cattaneo G, Esposti D, Esposti G, et al: Clinical study of melatonin in untreatable advanced cancer patients. Tumori 73: 475-480, 1987.

119. Grant SG, Melan MA, Latimer JJ and Witt-Enderby PA: Melatonin and breast cancer: Cellular mechanisms, clinical studies and future perspectives. Expert Rev Mol Med 11: e5, 2009.

120. Del Fabbro E, Dev R, Hui D, Palmer L and Bruera E: Effects of melatonin on appetite and other symptoms in patients with advanced cancer and cachexia: A double-blind placebo controlled trial. J Clin Oncol 31: 1271-1276, 2013.

121. Berk L, Berkey B, Rich T, Hrushesky W, Blask D, Gallagher M, Kudrimoti M, McGarry RC, Suh J and Mehta M: Randomized phase II trial of high-dose melatonin and radiation therapy for RPA class 2 patients with brain metastases (RTOG 0119). Int J Radiat Oncol Biol Phys 68: 852-857, 2007.

122. Lissoni P, Tancini G, Barni S, Paolorossi F, Ardizzoia A, Conti A and Maestroni G: Treatment of cancer chemotherapy-induced toxicity with the pineal hormone melatonin. Support Care Cancer 5: 126-129, 1997.

123. Vijayalaxmi, Thomas CR Jr, Reiter RJ and Herman TS: Melatonin: From basic research to cancer treatment clinics. J Clin Oncol 20: 2575-2601, 2002.

124. Lissoni P: Is there a role for melatonin in supportive care? Support Care Cancer 10: 110-116, 2002.

125. Lissoni $\mathrm{P}$, Barni S, Mandalà M, Ardizzoia A, Paolorossi $\mathrm{F}$, Vaghi M, Longarini R, Malugani F and Tancini G: Decreased toxicity and increased efficacy of cancer chemotherapy using the pineal hormone melatonin in metastatic solid tumour patients with poor clinical status. Eur J Cancer 35: 1688-1692, 1999.

126. Lissoni P, Chilelli M, Villa S, Cerizza L and Tancini G: Five years survival in metastatic non-small cell lung cancer patients treated with chemotherapy alone or chemotherapy and melatonin: A randomized trial. J Pineal Res 35: 12-15, 2003.

127. Sookprasert A, Johns NP, Phunmanee A, Pongthai P, Cheawchanwattana A, Johns J, Konsil J, Plaimee P, Porasuphatana S and Jitpimolmard S: Melatonin in patients with cancer receiving chemotherapy: A randomized, double-blind, placebo-controlled trial. Anticancer Res 34: 7327-7337, 2014.

128. Seely D, Wu P, Fritz H, Kennedy DA, Tsui T, Seely AJ and Mills E: Melatonin as adjuvant cancer care with and without chemotherapy: A systematic review and meta-analysis of randomized trials. Integr Cancer Ther 11: 293-303, 2012.

129. Wang YM, Jin BZ, Ai F, Duan CH, Lu YZ, Dong TF and Fu QL: The efficacy and safety of melatonin in concurrent chemotherapy or radiotherapy for solid tumors: A meta-analysis of randomized controlled trials. Cancer Chemother Pharmacol 69: 1213-1220, 2012.

130. Russo J and Russo IH: The role of estrogen in the initiation of breast cancer. J Steroid Biochem Mol Biol 102: 89-96, 2006.

131. Chakravarthi BV, Nepal S and Varambally S: Genomic and epigenomic alterations in cancer. Am J Pathol 186: 1724-1735, 2016.

132. Lee SE, Kim SJ, Youn JP, Hwang SY, Park CS and Park YS MicroRNA and gene expression analysis of melatonin-exposed human breast cancer cell lines indicating involvement of the anticancer effect. J Pineal Res 51: 345-352, 2011.

133. Lee SE, Kim SJ, Yoon HJ, Yu SY, Yang H, Jeong SI, Hwang SY, Park CS and Park YS: Genome-wide profiling in melatonin-exposed human breast cancer cell lines identifies differentially methylated genes involved in the anticancer effect of melatonin J Pineal Res 54: 80-88, 2013.

134. Dauchy RT, Xiang S, Mao L, Brimer S, Wren MA, Yuan L, Anbalagan M, Hauch A. Frasch T, Rowan BG, et al: Circadian and melatonin disruption by exposure to light at night drives intrinsic resistance to tamoxifen therapy in breast cancer. Cancer Res 74: 4099-4110, 2014.

135. Xiang S, Dauchy RT, Hauch A, Mao L, Yuan L, Wren MA, Belancio VP, Mondal D, Frasch T, Blask DE and Hill SM: Doxorubicin resistance in breast cancer is driven by light at night-induced disruption of the circadian melatonin signal. J Pineal Res 59: 60-69, 2015.

136. He SM, Li R, Kanwar JR and Zhou SF: Structural and functional properties of human multidrug resistance protein 1 (MRP1/ABCC1). Curr Med Chem 18: 439-481, 2011.
137. Granzotto M, Rapozzi V, Decorti G and Giraldi T: Effects of melatonin on doxorubicin cytotoxicity in sensitive and pleiotropically resistant tumor cells. J Pineal Res 31: 206-213, 2001.

138. Jardim-Perassi BV, Arbab AS, Ferreira LC, Borin TF, Varma NR, Iskander AS, Shankar A, Ali MM and de Campos Zuccari DA: Effect of melatonin on tumor growth and angiogenesis in xenograft model of breast cancer. PLoS One 9: e85311, 2014.

139. Woo SM, Min KJ and Kwon TK: Melatonin-mediated Bim up-regulation and cyclooxygenase-2 (COX-2) down-regulation enhances tunicamycin-induced apoptosis in MDA-MDB-231 cells. J Pineal Res 58: 310-320, 2015

140. Wang J, Xiao X, Zhang Y, Shi D, Chen W, Fu L, Liu L, Xie F, Kang T, Huang W and Deng W: Simultaneous modulation of COX-2, p300, Akt, and Apaf-1 signaling by melatonin to inhibit proliferation and induce apoptosis in breast cancer cells. J Pineal Res 53: 77-90, 2012

141. Proietti S, Cucina A, Dobrowolny G, D'Anselmi F, Dinicola S, Masiello MG, Pasqualato A, Palombo A, Morini V, Reiter RJ and Bizarri M: Melatonin down-regulates MDM2 gene expression and enhances p53 acetylation in MCF-7 cells. J Pineal Res 57: 120-129, 2014.

142. Yun M, Kim EO, Lee D, Kim JH, Kim J, Lee H, Lee J and Kim SH: Melatonin sensitizes H1975 non-small-cell lung cancer cells harboring a T790M-targeted epidermal growth factor receptor mutation to the tyrosine kinase inhibitor gefetinib. Cell Physiol Biochem 34: 865-872, 2014

143. Plaimee P, Weerapreeyakul N, Barusrux S and Johns NP: Melatonin potentiates cisplatin-induced apoptosis and cell cycle arrest in human lung adenocarcinoma cells. Cell Prolif 48: 67-77, 2015.

144. Pariente R, Pariente JA, Rodríguez AB and Espino J: Melatonin sensitizes human cervical cancer HeLa cells to cisplatin-induced cytotoxicity and apoptosis: Effects on oxidative stress and DNA fragmentation. J Pineal Res 60: 55-64, 2016.

145. Uguz AC, Cig B, Espino J, Bejarano I, Naziroglu M, Rodríguez $\mathrm{AB}$ and Pariente JA: Melatonin potentiates chemotherapy-induced cytotoxicity and apoptosis in rat pancreatic tumor cells. J Pineal Res 53: 91-98, 2012.

146. Yamanishi M, Narazaki H and Asano T: Melatonin overcomes resistance to clofarabine in two leukemic cell lines by increased expression of deoxycytidine kinase. Exp Hematol 43: 207-214, 2015.

147. Ma C, Li LX, Zhang Y, Xiang C, Ma T, Ma ZQ and Zhang ZP: Protective and sensitive effects of melatonin combined with Adriamycin on ER+ (estrogen receptor) breast cancer. Eur J Gynaecol Oncol 36: 197-202, 2015.

148. Ju HQ, Li H, Tian T, Lu YX, Bai L, Chen LZ, Sheng H, Mo HY, Zeng JB, Deng W, et al: Melatonin overcomes gemcitabine resistance in pancreatic ductal adenocarcinoma by abrogating nuclear factor- $\kappa \mathrm{B}$ activation. J Pineal Res 60: 27-38, 2016.

149. Kosar PA, Naziroğlu M, Övey IS and Çiğ B: Synergic effects of doxorubicin and melatonin on apoptosis and mitochondrial oxidative stress in MCF-7 breast cancer cells: Involvement of TRPV1 channels. J Membr Biol 249: 129-140, 2016.

150. Chuffa LG, Alves MS, Martínez M, Camargo IC, Pinheiro PF, Domeniconi RF, Júnior LA and Martinez FE: Apoptosis is triggered by melatonin in an in vivo model of ovarian carcinoma. Endocr Relat Cancer 23: 65-76, 2016.

151. Li W, Fan M, Chen Y, Zhao Q, Song C, Yan Y, Jin Y, Huang Z, Lin C and Wu J: Melatonin induces cell apoptosis in AGS cells through the activation of JNK and P38 MAPK and the suppression of nuclear factor-kappa B: A novel therapeutic implication for gastric cancer. Cell Physiol Biochem 37: 2323-2338, 2015.

152. Reiter RJ, Tamura H, Tan DX and Xu XY: Melatonin and the circadian system: Contributions to successful female reproduction. Fertil Steril 102: 321-328, 2014.

153. Ma Z, Yang Y, Fan C, Han J, Wang D, Di S, Hu W, Liu D, Li X, Reiter RJ and Yan X: Melatonin as a potential anticarcinogen for non-small-cell lung cancer. Oncotarget 7: 46768-46784, 2016.

154. Stover DG and Wagle N: Precision medicine in breast cancer: Genes, genomes, and the future of genomically driven treatments. Curr Oncol Rep 17: 15, 2015.

155. Sanchez-Barcelo EJ, Mediavilla MD, Alonso-Gonzalez C and Reiter RJ: Melatonin uses in oncology: Breast cancer prevention and reduction of the side effects of chemotherapy and radiation. Expert Opin Investig Drugs 21: 819-831, 2012. 